\title{
Exploring criteria for transformative policy capacity in the context of South Africa's biodiversity economy
}

\author{
Jan Janosch Förster ${ }^{1} \cdot$ Linda Downsborough $^{2} \cdot$ Lisa Biber-Freudenberger $^{1}$. \\ Girma Kelboro Mensuro $^{1}$. Jan Börner ${ }^{1}$
}

Published online: 29 April 2020

(C) The Author(s) 2020

\begin{abstract}
In the wake of increasingly complex sustainability challenges, societal transformations of currently unsustainable socio-economic production and consumption patterns are imperative. At the same time, international scholarly debates emphasise a decline in the policy capacity of societal actors to deal with the complexity of putting policy into practice. South Africa's national development strategy of utilising its unique biodiversity for developing natural products and biopharmaceuticals was anticipated by the government to help overcome the country's triple challenge of unemployment, poverty and inequality. Accompanied by a set of national regulations, introduced to safeguard biodiversity thresholds and regulate socio-economic activities along biomass value chains, this policy of a biodiversity economy is framed by the South African government, as a societal transformation. Informed by a plural theoretical lens drawing upon insights from international scholarly literature on transitions and transformations and insights from policy capacity, implementation research and governance literature, we interrogate qualitative empirical evidence from the field for how and whether such transformation has materialised for different bioprospecting actors in South Africa. Asking which factors enabled or limited this transformation, we distil criteria for what we call transformative policy capacity. We argue that transformations are political and deeply context-dependent relying on the resources and capabilities of involved societal actors to put political plans into practice, including the policy target group. We conclude that a biodiversity economy-driven transformation has yet to become a reality for many South Africans, but efforts are being made to foster the policy capacity of central actors and to adapt the regulatory system to be more conducive for the anticipated change.
\end{abstract}

Keywords Transformation · Bioeconomy · Bioprospecting · Governance - Implementation · South Africa

Jan Janosch Förster

jforster@uni-bonn.de

1 Centre for Development Research (ZEF), Rheinische Friedrich-Wilhelms-Universität Bonn, Genscherallee 3, 53113 Bonn, Germany

2 IIE MSA, School of Engineering, ICT, Science and Health, 144 Peter Rd, Ruimsig, Roodepoort 1724, South Africa 


\section{Introduction}

\section{South Africa's biodiversity economy}

Societies are confronted with a multitude of complex and unstructured policy and governance challenges worldwide, such as natural resources overuse, unprecedented rates of biodiversity loss and environmental degradation. For a healthy and sustainable future of current and future generations, more profound regime shifts are necessary (Chaffin et al. 2016; Rockström et al. 2009).

As a consequence, national governments are expected to develop their political strategies in line with the sustainable development imperative of our time: fostering inclusive socio-economic development and societal advancements without surpassing the planetary boundaries of a healthy biosphere (Rockström et al. 2009; Freudenberger et al. 2010). The formulation of a global set of Sustainable Development Goals (SDGs) reflects this governance challenge (Monkelbaan 2019).

As one potential pathway to address the SDGs, the concept of bioeconomy has gained relevance in research and policy debates over the last decade (see Dietz et al. 2018). Whilst there is no SDG dedicated to the bioeconomy per se, multiple sustainability goals are likely to be affected, positively or negatively, by bioeconomic growth. Definitions of bioeconomy in international literature vary across academic disciplines; a central purpose, however, underpins all of them: to provide alternatives to the current fossil fuel-based economy and related unsustainable patterns of production and consumption, by using products, processes and principles derived from biological resources.

South Africa's bioeconomy policy outlines the economic utilisation of its biodiversity as a national development strategy - the Biodiversity Economy. As one of the few megadiverse countries ${ }^{1}$ with traditional pools of ethnobotanical knowledge related to medicinal plants, ${ }^{2}$ South Africa's biodiversity holds considerable economic promise. ${ }^{3}$ Indeed, how to create inclusive employment opportunities within a national strategy addressing socio-economic inequalities (related to SDGs 1, 8, 10, 11 and 12) is the "hot potato" in South African politics and elsewhere. According to Dietz et al. (2018), 41 countries in the world have developed bioeconomy policies with a more prominent pro-poor focus in East Asia, Africa and Latin America. The Thai government for example has recently introduced a bioeconomy policy based on the utilisation of biodiversity and natural resources (i.e. cassava and sugarcane) with the overall goal of reducing poverty and including the marginalised poor and rural population. This pertains, besides a strong focus on biotechnology and industrial applications, to the development of bioeconomic products (i.e. bioplastic packaging), new

\footnotetext{
1 Countries that collectively hold over $70 \%$ of the world's biodiversity.

2 South Africa is one of the world's biodiversity-rich countries with more than 19500 indigenous plant species from around 350 plant families (Crouch et al. 2008). Not surprisingly, a large pool of traditional ethnobotanical and ethno-medicinal knowledge exists, especially regarding the use of plants (Lall 2018). Regional studies from Fourie et al. (1992) and Arnold et al. (2002) have shown that 243 of 300 evaluated medicinal plants show biological activity in a range of target assays with antiplasmodial activity. In other words, biological resources and related ethnobotanical indigenous knowledge constitute a promising starting point for medicinal bioprospecting for the development of natural products and drugs (Lall 2018).

${ }^{3}$ For example between 1981 and 2013, an average of $30 \%$ of worldwide drug developments was based on natural products (Wynberg et al. 2015). Apart from that, sizable economic potential is also attributed to non-medicinal bioprospecting for a growing world market of natural food and beverage products, fibre, botanical uses, biopesticides and organic personal care products (Laird et al. 2010; GVR 2019).
} 
cascading uses of agricultural waste, as well as trying to further initial projects in the farming of insects as protein-rich source for feed (Förster 2020).

In South Africa, "Biodiversity is an economic sector that can contribute to radical socio-economic transformation in South Africa [...] and the sustainable use of our biological resources for the economic benefit of our communities", said the Minister of Environmental Affairs in her public speech at the 3rd Biodiversity Economy Indaba in East London 2018 (Parliamentary Monitoring Group 2018a, b). For such benefits, the expected emergence of green entrepreneurs and the establishment of small and medium sized farming business by those historically disadvantaged had been a key political aspiration in the country's developmental agenda (Department of Environmental Affairs, DEA 2015a). Accordingly, the Biodiversity Economy policy strategy states: "The strategy aims to contribute to the reduction of poverty in rural areas through the development and capitalisation of resources and hidden skills currently available in areas where the poorest South Africans live, thus incorporating marginalised communities into the greater biodiversity economy" (DEA 2015a).

South Africa's biodiversity economy has two major components: the Wildlife Economy and the Bioprospecting Economy (DEA 2015a). The Wildlife Economy relates to the breeding and sale of animals; it includes value chains around wildlife activities such as tourism, trophy hunting and the management of protected areas and it is about wildlife products such as game meat, skins and hides or curio and jewellery production. The Bioprospecting Economy concerns the economic exploitation of non-animal biological and genetic resources in the cultivation, collection, processing, manufacturing and export, as well as the market and retail sectors, for example, of natural products such as creams and ointments or nutritional supplements. As such, South Africa's Bioprospecting Economy can be considered part of the health and trade related sectors of the country's 2013 Bioeconomy Strategy.

Bioprospecting involves balancing both legal and practically complex aspects, such as the protection of indigenous knowledge and biodiversity through property rights, access and benefit sharing, while achieving the overarching policy goal of creating inclusive economic opportunities for the development of bioprospecting businesses in South Africa. Livelihood strategies of small-scale bioprospecting businesses were anticipated to create platforms for the production and trade of natural (medicinal) products, as well as biobased inputs for biopharmaceuticals and personal care products (Laird et al. 2010; Lall 2018), linking local biomass growers to companies ('from farmer to pharma') and to offer alternative pathways for making a sustainable living for the poor (DST 2013; DEA 2018). However, the political strategy of promoting the Biodiversity Economy as a transformative socio-economic development strategy is strongly related to the country's developmental challenges (DST 2013; DEA 2018) and interwoven with its historical context.

A quarter of a century after the end of the Apartheid regime, the high hopes raised by the first democratically elected government of redressing the wrongs of the past through the creation of employment and alternative livelihood opportunities is yet to become a reality for many South Africans (Swatuk 2008; Schreiner and Hassan 2011). The country's large socio-economic inequalities of asymmetries in income and wealth distribution, as well as unequal access to natural resources, such as land and water are persistent (van Koppen et al. 2011; Schreiner 2013; Förster 2018). Unemployment levels sit at approximately $30 \%$ nationally with around 50\% unemployment for the under-30 (StatsSA 2019). These are significant societal challenges and contribute towards making South Africa one of the most unequal societies in the world with a Gini coefficient of 0.63 according to the (2013) UN Human Development Report. In order to address South Africa's "triple challenge of 
unemployment, poverty and inequality" (DEA Minister 2018), the political idea of a "radical transformation" ${ }^{4}$ has been used over the last 15 years as a political rhetoric to describe the aspired change since the first free elections in 1994 and the following ANC-led governments. ${ }^{5}$ The "transformation" envisaged by the South African government thus has a developmental and societal character of potentially providing policy opportunities and support for entrepreneurship in the bioprospecting sector.

However, transformations are inherently a matter of societal preferences and processes related to policy and governance (Smith and Stirling 2010; Grin 2010; Scoones et al. 2015; Rogge and Reichardt 2016; Göpel 2018). Although a large number of scholarly contributions highlight the importance of capacity for policy functions regarding transformations, scientific studies concretising policy capacities required to fuel transformative processes are rare (ibid.). Also, the 2019 SDG implementation report of the Bertelsmann Foundation and the SDSN (Sustainable Development Solutions Network) outlines limited policy capacity and challenges with implementing SDG-related policies as one of the central obstacles for SDG achievement in African countries (Sachs et al. 2019). As such, among numerous discourses on transformations, one question features prominently (for example, Markard et al. 2012; Patterson et al. 2016): how to steer transformative processes by means of policy and which kind of resources and capacities on which societal level are required?

This paper uses empirical insights on South Africa's Biodiversity Economy policy and subsequent regulations in practice to explore criteria for policy capacity in relation to societal transformations. Addressing the question of whether and how the South African government has used the existing policy capacity to put their normative developmental vision of a Bioprospecting Economy into practice and to initiate and steer a societal transformation, we investigate how such transformation has materialised for different bioprospecting actors and which factors enabled or limited this transformation, while extrapolating criteria for transformative policy capacity.

\section{Theoretical lens}

Theoretically, this article draws on well-known concepts from international scholarly literature on transitions and transformations and pairs them with insights of policy capacity, implementation research and governance literature. This plural and transdisciplinary perspective is necessary in order to align the multi-level complexity of governing ${ }^{6}$

\footnotetext{
4 Noteworthy, the term 'radical transformation' used here does not relate to the scholarly concept of addressing sustainability challenges (Patterson et al. 2016), but to the practical need of change (DST 2013; DEA 2018). It is an official term used by various ministers, as well as the former president Jakob Zuma and the current President Cyril Ramaphosa (EWN 2018; BusinessTech 2018) as the overarching goal of national development policy.

5 President Ramaphosa said the idea behind the concept of radical economic transformation was about building an inclusive and more collective economy in the country. The government would hope to create more sustainable growth, higher investment, increased employment and reduce economic inequality (GSB 2018).

6 In this article, we follow Benz et al. (2007, p. 105) in their understanding of governance as the attempt to coordinate societal action. Accordingly, we consider policy as an integral part of governance. Drawing on North (1990) and Giddens (1984), we differentiate between institutions, as tangible ones like policy and law, and intangible or immaterial ones, such as norms, belief/systems and social habits, as humanly devised 'things' envisaged to structure and coordinate human action in various ways. Employing institutional theory, one could attribute the former to formal institutions, while the latter two are often referred to as informal institutions (Peters and Pierre 2007; Benz et al. 2007).
} 
transformations in practice to the concepts used to analyse them (Rueschemeyer 2009). Furthermore, related international scholarly literature on governing transformations (and transitions) often takes a conceptually descriptive and analytically macro-level perspective, whereas one jointed with concrete examples of policies in societal praxis are limited (Svensson and Nikoleris 2018).

\section{Transformations and transitions towards sustainability}

Frequently labelled as transformations or transitions in international scholarship, grand societal shifts (Polanyi 2001) have come to the forefront of sustainability science (Schot and Geels 2008; Grin et al. 2010). Related literature conceptualises the inherent systemic connections between humans and nature (socio-ecological systems, Olsson et al. 2004, 2006; Gunderson and Holling 2002; Parsons 2004; Smith and Stirling 2010) and humans and our technical systems (socio-technical systems, Geels and Schot 2010; Rotmans and Loorbach 2009; Schot and Kanger 2018) as two different, but interdependent systems. Established technologies are highly intertwined with user life styles and livelihoods, while both, ultimately and existentially, depend on healthy ecological functions of the giant ecosystem called Earth and its manifold subsystems (Loorbach 2009; Raworth 2012). This can be described as a socio-ecological-technical system (SETS) (Göpel 2018).

In this view, transformations relate to processes of change in societies, ${ }^{7}$ which is anticipated to overcome ecologically harmful socio-economic and socio-technical practices, and to develop alternative technological innovations and societal practices including new or different institutional "rules of the game" (Meadowcroft 2009; Loorbach and Rotmans 2010; Frantzeskaki et al. 2012). A transformation thus refers to a web of processes of change created and fuelled through the coevolution of economic, ecological, cultural, technological and institutional developments at different scales involving multiple actors on multiple societal levels (ibid.).

This makes transformations inherently complex and dynamic with outcomes all but certain (Loorbach 2009). However, since transformations are a matter of societal choices (Rogge and Reichardt 2016), questions of steering transformations are to a large degree socio-political in character (Grin et al. 2010). For Markard et al. (2012), "one of the main challenges in this field therefore is to improve the understanding of how policies can influence transitions".

Researchers using SETS-related concepts frequently highlight the central importance of "capacities" and "abilities" for steering transformations (Smith and Stirling 2010; Westley et al. 2013). However, limited policy capacity is often times the socio-political reality for a large number of governments in developing countries, where financial and human skills-related capacity deficits are more prominent and persistent (Ribot 2009; BTI 2019). As such, the desired steering effect of policy on transformations often means a strong involvement of state actors, and this stands in stark contrast to the existing capacities of such actors in practice. Perceptions that governments and public administrations have lost policy capacity have been pervasive (Chess et al. 2000; Peters 2015), and "executive capacity" and "strategic capacity" have been high on the agenda of various international

\footnotetext{
7 This is because SETS-related societal structures are relatively resistant to change and global sustainability challenges sketched above, are linked to (and intensified) by strong path-dependencies and lock-in effects observed in socioeconomic practices (Göpel 2018), which have significant repercussions for socio-ecological systems (Raworth 2012).
} 
organisations over the last decade, such as the UN, UNEP or the OECD (OECD 2006, 2012, 2015; UNEP 2018; BTI 2019). Concerns about the ability of government's administrative units to perform adequately in the wake of complex sustainability challenges have been given a number of labels over the last ten years including capacity, competency and capability, or has been discussed under the label of implementation failures(Parsons 2004; Howlett and Lindquist 2004; Howlett and Ramesh 2015).

The question of how to expediently govern transformative processes and purposefully 'steer' societal systems towards greater sustainability is thus, ultimately, linked to the capacity of government actors to devise, implement and adapt institutional arrangements and legal prescriptions of a certain policy mix, ${ }^{8}$ while keeping a keen eye on social realities in everyday governance practices and the abilities of the societal actors to understand and utilise the offers from policy. Such steering' has been categorised as: (i) preparedness and preparing a system for change; (ii) strategic management in windows of opportunity through policy and governance, and (iii) the consolidation of the newly emerging regime (see also Olsson et al. 2004, 2006; Folke et al. 2005, 2010; Chapin et al. 2009; Loorbach and Rotmans 2010). In our results discussion, we will analytically reflect on these and the following categories in relation to empirical evidence.

Also, in order to help further understand how to steer transformative processes, we use Patterson et al. (2016) typology of governance for and of transformations. Policy and governance for transformations is defined as a form of enabling policy central to achieve societal empowerment, poverty reduction and socio-economic growth (see Dietz et al. 2018). Governance of transformations encompasses maintaining a transformative momentum by triggering, incentivising and steering transformative processes, while using constraining, regulatory instruments ${ }^{9}$ of policy and governance where necessary to keep societal developments within planetary boundaries. Transformations of policy and governance thus refer to policy change and adaptation of governance systems (see also Biermann et al. 2009; Patterson et al. 2016). In this article, we mainly focus on the first category of policy for transformations, while using transformations of policy for highlighting recent changes in related South African policy processes.

\section{Exploring policy capacity for transformations}

Policy and governance for transformations is about creating conditions that enable transformative processes to emerge from existing social, technical, ecological and economic systems. This includes creating awareness; developing capacity within public authorities, societal actors and within specific policy target groups; devising supporting legislation and policy guidelines; and establishing financial support mechanisms and institutions for transformative socio-economic dynamics to emerge (Loorbach and Rotmans 2010; Göpel 2018). Also, the socio-political processes involved in developing transparency, accountability and legitimacy are key ingredients to policy processes influencing their implementation and institutional effectiveness (Biermann et al. 2009).

\footnotetext{
8 We outline ideas of transformative policy capacity while suggesting their compatibility with concepts of policy mixes (Rogge and Reichardt 2016; Edmondson et al. 2018).

${ }^{9}$ Regulation in this paper broadly refers to instruments ranging from classical, state-driven forms of legal regulation to different forms of self-regulation and co-regulation designed to guide certain activities of actors (Kooimann 2003). The intention to regulate and govern something, we assert to be to coordinate and steer societal developments towards achieving a set of politically aspired goals (see also Förster et al. 2017).
} 
However, in the past, scholars often viewed policy implementation as a result of government's capacity for effective administration (Fukuyama 2013; Peters 2015). Traditionally, this often included the notion of policy makers assuming it sufficient to "design" a new framework for a policy or law, while its implementation, would just magically follow (Bressers and O'Toole 1998; Houtzagers 1999; deLeon and deLeon 2002). However, Shove and Walker (2010) indicate that "much of the governance literature, including that of a more reflexive bent, supposes a distinction between 'us' and 'them', implying scenarios in which one set of actors is governed by another" (ibid.). However, in our view, such dichotomist distinctions do rarely reflect socially complex everyday realities of policy and governance (Kooimann 2003; Shove and Walker 2010; Cleaver 2012; van der Molen 2018). Indeed, international evidence suggests that the way policies "play out" in practice depends to a greater extent on conditions and contexts found in reality and on the cognitive and practical operational capacities of involved individuals, groups and organisations than on the way the policy was normatively "designed" (Lipsky 1980; see also Sabatier and Jenkins-Smith 1993; Houtzagers 1999; Boelens and Zwarteveen 2005; Cleaver 2012; van der Molen 2018). As Parsons (2004) outlined, it is more about weaving different parts of normative ideas expressed in policies together with everyday social realities, into a societal fabric.

Policy capacity has been referred to in a broad sense as the ability of a government to make choices of resource distribution (see Lasswell 1936, in Muno 2007; Painter and Pierre 2005; Fukuyama 2013); to set strategic directions after assessing the context (Howlett and Lindquist 2004; Howlett and Ramesh 2015); to put forward alternative policy pathways (Altvater 2009); and making expedient policy decisions on the basis of evidencebased knowledge (Parsons 2004; Painter and Pierre 2005). In our results section and conclusion, we will draw on these concepts to discuss the empirical evidence.

Policy capacity has lately gained increased academic attention as a concept to address increasingly complex problems (Peters 2015; Wu et al. 2015). Knowledge and skills to derive and implement evidence-based strategies to answer policy challenges and to effectively communicate them to involved actors are therefore central to the concept of policy capacity or governance capacity (Howlett 2009; Westley et al. 2013; Howlett and Ramesh 2015; van der Molen 2018; Forst 2018).

Embracing a multi-level perspective, common to transformations and transitions studies, we use Wu et al.'s (2015) conceptualisation of policy capacity on the intersection of different levels of capacity (individual, organisational and systemic) and policy dimensions (analytical, operational and contextual) as illustrated in (Fig. 1). We define policy capacity drawing on Wu et al. (2015) and Gleeson et al. $(2009,2011)$ as a set of resources and capabilities central to perform policy functions. ${ }^{10}$

In this paper, we thus use the model categories as shown in Fig. 1 as a guiding heuristic. This informed the process of data collection and analysis, as well as the structure of the results section.

Firstly, capacities from the analytical level support evidence-based policy making and refer to ensuring the achievement of policy objectives, by suggesting or choosing expedient strategies and policy mixes. They relate to education, knowledge and other sets of skills and competences. This level of capacity plays a pivotal role in understanding the magnitude of

\footnotetext{
10 This definition is not limited to specific functions, but rather pertains to all policy processes ranging from agenda setting and the development and formulation of a policy to rule setting, to implementation and monitoring.
} 
Fig. 1 Nested model of policy capacity (Wu et al. 2015)

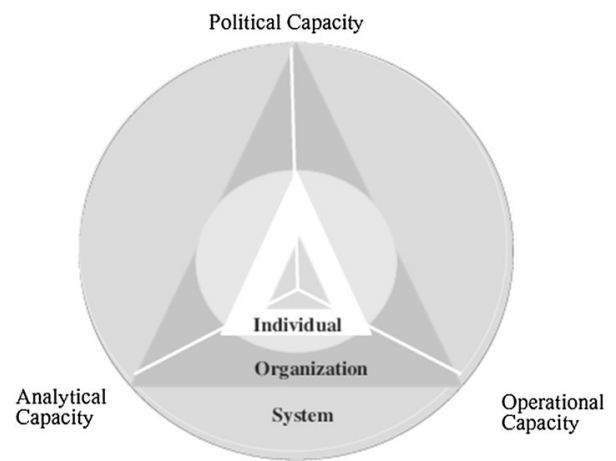

sustainability-related transformation challenges, while making technically sound (sectoral) policy choices in the individual-operational and the organisational-operational levels(Wu et al. 2015). Secondly, operational-level capacities relate to the endowment with expedient and rather managerial resources and capacities and their timely allocation and use in policy processes (see also Laswell 1958 in Muno 2007) while acknowledging policy trade-offs for the implementation of policies in everyday situations (Peters 2015). This relates to numbers of qualified staff, in relation to workload, but also to technical and specialised knowledge about the topic at hand (Wu et al. 2015). Thirdly, capacity from the systemic level consists of obtaining and maintaining long-term political support on a systemic level following a shared vision; furthering systemic knowledge within policy processes and related actors on an organisational level; the strategic coordination according to forecasted societal scenarios; long-term collaboration of state actors and other relevant societal actors for coherency and the existence of institutionalised processes of reflective learning in triple feedback loops to develop a strategic capacity with key actors (Pahl-Wostl 2009; Rotberg 2014; Peters 2015; Monkelbaan 2019). The systemic level furthermore relates to the national level of political and practical support structures for societal actors and the broader nature of the social and economic systemic patterns, but also to the existence of a shared and socially acknowledged vision of the future (ibid.).

In order to bridge the more conceptual divide between capacity levels, we assert and focus on the notion introduced earlier that "preparing the system for change" is among the most central tasks of government by creating strategic agency: to develop a critical mass of resourceful, skilled and knowledgeable people with a set of capacities to access, understand and make use of policy opportunities for their benefit and that of others (Archer 2000; see also Göpel 2018).

This multi-dimensional view allows for an understanding of the multi-level character of policy and governance, in which some capacities might be more critical than others in certain policy fields or country contexts and at varied time and spatial scales. Surely, the levels of capacity influence each other in this nested model of capacities, where system level resources of the state affect organisational ones and vice versa. Similarly, individual and organisational resources can act in concert. 


\section{Methods}

This paper presents empirical results that are comparable and methodologically replicable, with relevance to similar contexts. Drawing on empirical results of the field research in the South Africa's bioprospecting economy, we explore criteria for transformative policy capacity by analysing a potentially transformational policy.

We contrast the transformative intentions of the South African Biodiversity Economy policy and the regulatory intentions of the two most relevant pieces of legislation the National Environmental Management and Biodiversity Act (NEMBA) and the Bioprospecting Access and Benefit Sharing regulations (BABS)with empirical findings from the field (DEAT 2004). A systematic analysis of these policy documents (Given 2008; Du Plooy-Cilliers et al. 2014) provided the foundation for two field visits to South Africa in 2017 and 2018. During this time, the main author conducted 18 qualitative semi-structured and focus group interviews (Creswell 2009) with 32 research participants. These participants were selected based on their professional experience (at least three years) and their professional affiliation to the bioprospecting and natural product sector active in South Africa. Therefore, a purposive sampling technique was initially used followed by a snow ball sampling technique (Babbie 2007).

Participants chosen for this research traversed different levels of society from government, academia, research and consultancy, as well as other civil society organisations (“Appendix"). While recorded interviews were transcribed word for word (Flick 2006), interviews documented in field notes were contextualised and triangulated with data from other interviews, newspaper articles, government reports and international research institutes (Polkinghorne 2005; Bryman and Cassell 2006). Analysis and interpretation of the data were conducted using different techniques of open and theoretical coding (Creswell 2009; deVos et al. 2012). Linking theory to practice, we used the main coded themes which had inductively emerged as central from the data (limited capacity) and substantiated it theoretically to become the main analytical theme for this paper.

We use the model of policy capacity introduced earlier (Fig. 1) as an ordering heuristic to structure the results section. As such, the aim of this approach was not the development of a new theory, but to offer evidence-based and theory-informed insights of exploring what we assert as a pivotal ingredient for steering transformative processes/policy capacity.

In order to contextualise this research and as a starting point for discussing our results of the field research, we now embed South Africa's Biodiversity Economy within the broader country context of bioprospecting and within relevant international and national regulations.

\section{Bioprospecting in South Africa: key issues and related legislation}

The term bioprospecting' in South Africa includes any research on, or development or application of, biological resources for commercial or industrial exploitation. In the past, associated financial benefits were mainly reaped overseas, instead of providing for economically viable and inclusive business models ${ }^{11}$ (Crouch et al. 2008). Due to the influence

\footnotetext{
11 Notwithstanding, the natural product sector in South Africa using plant material from Rooibos, Pelargonium Sidoides and Moringa, as well as from Baobab and Aloe Ferrox for natural products has produced successful businesses in some local instances (Wynberg et al. 2015). However, such successful projects involved the support of knowledgeable and resourceful actors from inside or outside the project (Wynberg et al. 2015; Laird et al. 2010; Interview J).
} 


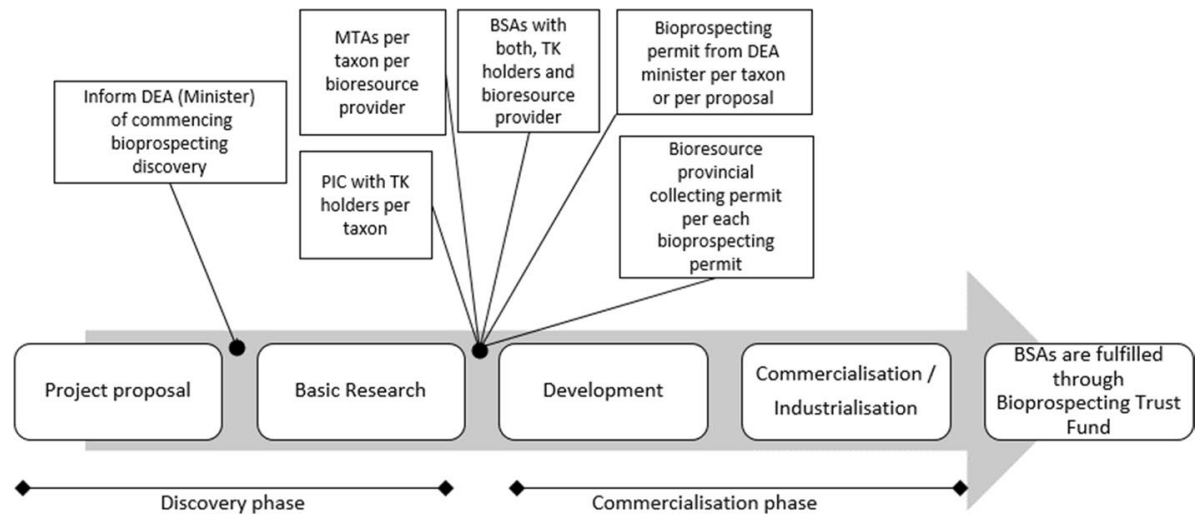

Fig. 2 The permit requirements for bioprospecting project phases (adapted from Crouch et al. 2008; Wynberg et al. 2015)

of international negotiations around the Convention on Biological Diversity (CBD), rather strict bioprospecting regulations were formulated with the intent to tighten national control over bioresources and to provide for more equitable and sustainable pathways of regulating access to biological resources and the commercial trade of natural products (DEAT 2008).

The international agreement supplementing the CBD-the Nagoya Protocol ${ }^{12}$ - provided the legal guardrails for the South African Biodiversity Economy policy. As such, sectoral regulation was strengthened through the National Environmental Management and Biodiversity Act (NEMBA) ${ }^{13}$ and the Bioprospecting Access and Benefit Sharing regulations (BABS). ${ }^{14}$ As part of these new regulations, a formalised permit system was established, under which relevant permits and agreements are to be obtained prior to any practical steps of commercialisation for bioprospecting and biotrade projects (Fig. 2).

Such projects have a discovery and a commercialising phase (in terms of South African law). Companies active in the discovery phase of identifying suitable plant species and related knowledge have to notify the DEA (Department of Environmental Affairs) using the official form. After the identification of a biological or genetic resource in the discovery phase, a prior informed consent (PIC) needs to be obtained by companies (or any economic actor) from all land and bioresource owners and holders of related traditional knowledge (TK). Benefit sharing agreements (BSAs) must be signed with relevant communities prior

\footnotetext{
12 The Nagoya Protocol to the 1995 Convention on Biological Diversity (CBD) was ratified by South Africa in 2013 and entered into force in 2014. It builds on the access and benefit sharing (ABS) principles in the $\mathrm{CBD}$. The establishment of the $\mathrm{ABS}$ - Clearing House (ABSCH) organisation (with a monitoring and advisory function to NAGOYA implementing countries) - offers signatory parties a communication platform regarding ABS implementation. However, these efforts of institutionalized communication on a digital platform have brought little advancements. Notably, 100 ratifying countries had pledged to implement the Nagoya Protocol in national legislation, but not more than 10 of them have actually translated it into national law (ABSCH website 2018).

13 NEMBA and BABS also gave effect to the international agreements of CITES (Convention on International Trade of Endangered Species) and TOPS (Trade of Protected Species). South Africa has signed, but not ratified, the International Treaty for Plant Genetic Resources for Food and Agriculture.

14 The (potentially) arising benefits can be royalties, knowledge and technology transfer and capacity building (see also Nkahta et al. 2012).
} 
to any activities related to the commercialising phase of a project. In addition, a material transfer agreement (MTA) must be signed between the bioresource owners and the bioprospecting company, as well as another separate BSA between company and TK-holder.

These documents must be attached to the bioprospecting permit application and submitted to the Minister (DEA) accompanied by a non-refundable fee of R 5000 (approx. 320€) per application. If successful, applicants must also seek the approval of the provincial government and obtain a bioprospecting collection permit from provincial authorities (see also Crouch et al. 2008; Laird et al. 2010). The potential revenues generated and shared between companies, bioresource providers and TK-holders are to be paid into a Bioprospecting Trust Fund administered ${ }^{15}$ by the national DEA.

The BABS regulations define bioprospecting as "growing, collecting, processing, researching, exporting, developing and manufacturing inputs, ingredients and products using South African biodiversity" (UEBT 2017, p. 2). This means that actors engaging in one or more value chain activities are required to obtain related permits for each activity defined as bioprospecting (Table 1 of the Appendix). However, in South African everyday practice, identifying the holders of traditional knowledge and negotiating access agreements with bioresource owners are not straightforward processes and proved lengthy and

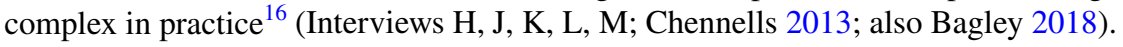

This is partly because, under South African legislation, the state does not own biological or genetic resources. These belong to landowners on whose property the resource happens to be found, including communal land ownership arrangements (Crouch et al. 2008). Due to forced relocations into so-called "homelands" during the Apartheid regime, the indigenous owners and traditional occupants of a piece of land are oftentimes scattered across different parts of the country (Quibble et al. 2012). Due to this, TK-holders of a bioresource in traditional communities might no longer be living in the area, where they or their ancestors had lived and used the bioresources traditionally. Land access and ownership rights and practices remain a highly sensitive topic in the country ${ }^{17}$ (OECD 2008; Swatuk 2008; Förster and Virgin 2018). Due to institutionalized race-based access and property rights of the past (van Koppen et al. 2011), a number of land claims and lawsuits concerning traditional black and Apartheid-white ownership of land are currently ongoing (Förster 2018). Both, the highly topical issue of negotiating PICs with traditional communities and obtaining permissions to access land, as well as the identification of TK-holders, makes attributing property rights and ABS compliant bioprospecting activities in practice a complex administrative procedure (see Bagley 2018).

The above findings of legal definitions, regulatory requirements from the permit system and related administrative procedures regarding bioprospecting in the history-laden

\footnotetext{
15 In South Africa, such benefits seldom come in the form of money, but rather in form of municipal projects and according infrastructure grants supposed to benefit the bioresource or TK-holder. According to a senior official from the DST, "no money has ever been paid to any community" (Interview B). Chennells (2013) also documented that such revenues had in some instances not been paid into the Trust Fund, but been channelled illegally to other involved entities.

16 This relates to a number of interconnected conflicting issues: first, traditional history and indigenous knowledge was often passed on orally. Secondly, this knowledge was collectively rather than privately owned. Third, concepts of formalized knowledge archives and individual ownership over natural resources based on written letters on a piece of paper often do not align with traditional realities (see also Wynberg et al. 2007).

17 For example, the South African president announced that the ANC-led government was discussing a motion for the expropriation of land owned by white people without compensation (News24 2019 , 12.05.2019).
} 
South African context, are now put into relation with our empirical results regarding policy capacity. In the following, we analyse how policy capacities found in practice have either fostered or inhibited the aspired societal transformation.

\section{Policy capacity for transformations}

Our results show that progress towards fostering socio-economic gains in South Africa's Bioprospecting and Biodiversity Economy benefitting the poor, while generating a conducive environment for natural product and pharmaceutical companies, has been hampered by a web of factors. Based on the results, we identify limited capacity in the dimensions of organisational-operational and systemic policy capacity in administrative units of the government as well as in the policy target group. Governmental actors from the Department of Environmental Affairs (DEA) had limited capacities in terms of human and financial resources, while those supposed to benefit from the new policy either had insufficient knowledge about its existence, or had inadequate knowledge and skills to utilise it for their benefit. We also found the broad definitions of bioprospecting in South African legislation to be limiting its implementation in practice. The regulatory requirements of the permit system were described as overly restrictive and combined with a limited policy capacity, were seen as an obstacle to the envisaged socio-economic developments in the bioprospecting sector.

\section{Limited organisational-operational policy capacity}

National departments who were interviewed, seemed to struggle financially, while they also lacked sufficiently skilled people with technical and specialised knowledge to fulfil their political mandate (Interviews A-C; see also Schreiner 2013). A lack of accountability and efficiency in national and local permitting authorities were pointed out by participants as large bureaucratic obstacles to put business ideas into practice. This lack of accountability, relates to all levels of government, but increases on lower levels of the federally organised public administration (ibid.). The representative of a natural product company explained (Interview I; also K): "The further down you go to provincial level, or further down [to municipal level] the less accountable the people you'll find there. Corruption is a big issue". Similarly, Laird et al. (2010, p. 321) noted "law enforcement capacity is low, the legal procedures are cumbersome and seemingly full of loopholes, and the low penalties do not constitute a deterrent to transgressors". A senior official from the South African DEA in the bioprospecting permit office, described the biggest challenge to successful implementation of national policy as "insufficient human resource capacity" (ABSCH website 2018). The CEO of a large South African natural product company said: "The issues we're facing is that, we've got too small departments, with too few people and too little capacity" (Interview M).

During numerous conversations and interviews with government actors, it became apparent that only three staff members dealt with the permit applications, while also performing other tasks such as organising conferences and other outreach activities. According to Bagley (2018), the number of bioprospecting permit applications had increased to 30 per year by the end of 2017, with an average processing time of up to 120 days each. In line with this, referring to financial resources and human capabilities, as well as interdepartmental coordination for policy implementation, a senior representative of the South 
African government said: "No, we do not have the capacity to do what is required by the acts" (Interview C). This confirms earlier notions in South African literature by Crouch et al. (2008), Wynberg et al. (2015, p. 560) and Bagley (2018) of limited operational policy capacity in authorities, hindering effective policy implementation in practice.

Data from well-known international research institutes also corroborate our findings. Policy capacity and implementation quality of South Africa's government structures and subsequent lower level public authorities has declined in the last 10 years in country assessments of worldwide governance indices (WGI 2019; BTI 2019). The Bertelsmann Transformation Index (BTI) attests South Africa a rather good governance performance occupying the 28th place among African countries, but outlines "functional flaws"(BTI 2019 ) in the index's more fine-grained categories of "steering capability" and "resource efficiency" in policy implementation.

\section{Unclear and broad definitions}

Unclear or overly broad legal formulations can cause uncertainty for large or small-scale actors in the bioprospecting economy alike, whereas clear definitions and transparent procedures with defined administrative timelines support the emergence of economic dynamics providing reliability (Tallberg 2002).

In South African legislation, two terms were central for bioprospecting in practice: "commercialisation" and "indigenous community". We earlier outlined the challenges we found with identifying the "right" indigenous community as holders of the traditional ethnobotanical knowledge and how they may no longer reside on the land in question. Commercialisation refers to the phase during which value addition occurs, or rather is anticipated to happen, and thus to the phase in, or after, which financial value is to be generated and then shared. This phase itself is not defined in South African legislation. As such, the point in time when potentially arising benefits can be shared is thus left undefined or remains overly vague. Confusion has also been caused in the permitting application process as actors are not sure, at which point in time of a project they are required to apply for a bioprospecting permit (Interviews J; K; L; M). Similarly, the question of whether the buyer of bioresources requires a bioprospecting permit or the actual grower, or both, is unclear (DEA 2015b). We furthermore found that the overly broad definition of bioprospecting led to a number of additional challenges of regulations and how they unfold in practice.

\section{Overregulated permit system}

Under NEMBA and BABS, "bioprospecting" generally refers to research on, development of, application of and processing of indigenous bioresources for a commercial or industrial purpose. This means that a large number of regulatory requirements have to be met by companies in the bioprospecting economy, prior to any other development (Fig. 2). Each bioprospecting application requires a separate permit at a non-refundable cost of R 5000 . A consultant for the CDB during the Nagoya Protocol negotiations explained that " $B A B S$ in practice means requiring a permit in every step of the value chain" (pers. com. March 2018, East London).

Indeed, the wide definition of bioprospecting in South African legislation had led to a bureaucratic overload with permit requirements. A natural product company working with rural communities in Baobab value chains said: "There are multiple problems with the regulations. The most import one is that everybody involved in the value chain requires a 
permit. So, I have a permit, [...] which is based on an [BSA] agreement with the harvesters. So, I sell to the next person on the value chain, let's say the distributor. They buy a number of oils from different players, whether it's lavender oil or whatever, and need a permit as well. Then, if they sell to somebody else, say a manufacturer, the manufacturer also needs a permit. If the manufacturer sells a[subsequent] cosmetic ingredient to a producer, to a brand owner, they also need a permit.

Now can you imagine the paper work around - and that simply to mix the natural ingredient into soap or to mix it into body butter. So it's nuts", the participant concluded "imagine what that does to a simple value chain, it becomes almost unmanageable" (Interview $\mathrm{J})$.

The CEO of an internationally exporting natural product company explained: “we've seen significant negative impacts on a lot of potential clients. Where people will go through the process to test the product [...] and then see a big scary warning at the Department [of Environmental Affairs] that if you don't have this [permit], you can't go ahead. So they just leave" (Interview K). This was confirmed by the CEO of a hair product company in Pretoria producing for the South African market explaining that "the only problem that I have personally with the regulation is that, it's a lengthy process with some uncertainties. It delays your business a lot" (Interview L).

Lengthy administrative procedures were discouraging and potentially endangering the viability of business models and financing plans of potential entrepreneurs starting a new bioprospecting-related business, especially as this was a field where actors "constantly race for patents" (Ladzani and Netswera 2009). The respondents from the larger international companies, as well as a natural product company working with rural communities emphasised the impacts of limited capacity (March 2018, East London 2018) "The regulators don't seem to understand the practical implications of this permitting system" (Interview $\mathrm{K})$.

Also, the requirement of a community to develop a "community protocol" is an important requirement stemming from the Nagoya Protocol for the protection of intellectual property rights of indigenous people. It also serves as a participatory tool for decisionmaking, but this process has proven to be a lengthy and cumbersome. In a sector in which quick pioneering decisions have to be made, this is not necessarily an optimal economic solution (Crouch et al. 2008). However, from a social and ethical point of view, this has been described as a positive development of acknowledging the ownership of indigenous knowledge and strengthened the negotiation position of TK holders in mostly rural communities and traditional ethnic groups (Interviews Q, R and S). These groups felt more involved and acknowledged, and perceived the ABS regulations a step into the right direction, despite an explicitly voiced critique on how the regulations are implemented in practice and about their limited participation in formulating them in the first place (ibid.).

This timely dimension is also important as it indicates that the regulations in practice have not provided "enabling governance" and a conducive environment, but rather administrative obstacles discouraging potential investors and cooperation partners: "Now, who has got so much patience and time? For example, the University of Pretoria has got a permit for some certain time. So, by the time our manufacturing partner gets a permit, our permit expires and we're back to square one. Products simply won't reach market and permits expire after half a year" (Interview F). Another company CEO told us: "We make natural hair care products using African indigenous ingredients. We started in 2015 [...], but we've only seriously been in the market since last year. [...]. I have no idea how long it takes for a permit, because I still haven't got one” (Interview L). 
This and the above findings regarding limited capacity show that smaller companies sometimes could not commence their business compliant with NEMBA and BABS regulations, while larger companies have a somewhat more privileged access. For example, a research participant from a large international company described the following situation regarding enforcement and control of regulations by the DEA: "I've been talking to them [the DEA]. They know me very well. The relationship that I have with them is of a nature that I can tell them that I am operating illegally. They also know that I've signed everything that I can to comply as good as possible. So, they leave me alone. I don't have any legal challenges from them on my plate" (Interview M). This describes a paradox situation, in which government officials from the DEA were aware of the challenges the regulations caused and chose to let companies operate nonetheless within a legal grey zone. It also indicates that large international players had privileged access to the permit system. Wynberg et al. (2015, p. 208) has similarly found that "onerous permit requirements, for example, have led to the creation of monopolies in some instances (for those companies who do receive permits) with negative impacts on communities and other companies (who do not receive permits)".

\section{Limited systemic policy capacity}

We sketched above that preparing "the system" for change, in societal transformations can be seen as the strategic management of skills development and the setting of incentives to create and manage windows of transformative opportunity. In the case of South Africa's Biodiversity Economy, this could have meant to increase levels of knowledge and skills in order to enable people to become an active player in the Bioprospecting Economy. This also refers to creating a conducive policy environment enabling people in the policy target group to benefit from its socio-political offers of becoming bioprospecting entrepreneurs. Regarding the capacity of the policy target group to make use of policy offers, a senior manager from South Africa's well-known Agricultural Research Council (ARC) expressed that "the know how is just not there from the farming community on a local basis. We need a massive community upliftment training and educational programs because, remember these are not necessarily conventional crops". He continued, "the whole education and training and empowering the farmers is what the government needs to do as a basic requirement. Government needs to really invest in terms of uplifting communities and educating and training communities" (Interview E).

The public capacity deficit documented in previous sections had implications for organising and initiating for transformations in long-term planning and the building of strategic capacity for change (Department for Planning, Monitoring and Evaluation, DPME 2015). It was argued that over the last 20 years the viability of newly established small and medium-sized enterprises (SMEs) was significantly influenced by the limited capacity of Departments to issue licenses and permits, as well as other issues of administrative governance in regional and local municipal services (Smallbone et al. 1995; Smedlund 2008; Shree and Urban 2012).

Correspondingly, we found that lengthy administrative procedures between four months and two years for a bioprospecting permit to be issued (Interviews I-J), caused significant planning uncertainties is hindering for an economic sector supposed to emerge with new market entrances (Loorbach 2009). We also found that regulatory hurdles and sluggish administrative governance, due to the largely limited financial resources and human capabilities of actors, have also resulted in weakened economic bioprospecting activities of 
the policy target group: "That makes it very difficult for small business; it doesn't promote small business doing this. But it rather gives people the idea that it's too difficult to go down that route" (Interview $\mathrm{K}$; also J). Our results thus confirm the anticipated negative effects of the new BABS regulations of Crouch et al. (2008, p. 357 and 358 in particular) on the socio-economic success of bioprospecting in South Africa (also Bagley 2018).

Also, the non-refundable fee of R 5000 (approximately $320 €$ ) was reported to be a high financial bureaucratic obstacle in a country where the daily minimum wage for low-skilled farm workers is R 105 (approx. 6,70 €). "Many of them [poor and rural communities] don't haveR5 000 for applying for permit that might not even come through. But they still have to continue to survive" said the founder ${ }^{18}$ of a small natural product company producing herbal beverages for South African markets (Interview I). Indeed, smaller businesses, often comprised of local growers of Moringa, Baobab, Buchu or Rooibos, had to operate "below the radar". In effect, "many small companies do it [activities that fall under bioprospecting and BABS regulations] without worrying about the regulations, it's impossible for them in the beginning" (Interview M).

Asah et al. (2015) reported that overly restrictive bureaucracy, over-regulation, red tape and lack of entrepreneurial knowledge and skills are key obstacles to sustained growth and development to start-up enterprises and potentially newly founded SMEs in all economic sectors of South Africa. This research supports that argument, while adding the factor of limited capacity of people on the ground in everyday situations to benefit from existing legislation and policy. Brownlie et al. (2017) have reported similar findings of a limited public policy capacity regarding interdepartmental coordination, inconsistent decisionmaking, policy implementation and rule enforcement and financial management of (provincial and local) public authorities in the policy field of biodiversity conservation and offset management.

The participant from the ARC quoted earlier also said: "The other area, is the regulatory processes-especially, [...] not to over-manage the value chain, but putting very firm rules and regulations in place [...]". As a third priority area for public policy action, the senior manager highlighted the limited financial support to small-scale projects as inevitable conditions for change "the government might want to put in a little bit more of seed funding [...], initial capital at least to get the first batch of entrepreneurs or enterprises going". This confirms that national public capacity on a systemic-operational level to foster the preparation of the system for change, here, by capacitating the policy target group as central actors, was largely limited.

Apart from that, systemic-operational policy capacity refers to the state of public support and capacity building through educational facilities, awareness raising and a functioning uptake of knowledge generated at ground level into decision-making at policy level (Wu et al. 2015). The indispensable foundation, however, of a successful business, whether small or large, consists of entrepreneurial knowledge and business skills. As such, this might be among the most important policy capacities for a sustainable development transformation in South Africa.

\footnotetext{
${ }^{18}$ He explained to have been fortunate. Besides his academic business management degree from an overseas university, he had personal contacts into the DEA, which helped to establish more formal relations. Two other participants of this research also reported that personal relations to the DEA permit offices had helped them establishing a business.
} 
Besides the results presented thus far, such knowledge and skills, were largely limited in poverty-stricken rural communities and small local towns of South Africa ${ }^{19}$ (Förster 2018). The Small Enterprise Development Agency (SEDA) of South Africa established in early 2004 has, for example, highlighted that by 2013, 60-70\% of all newly established small businesses in South Africa failed within their first year of operation (SEDA 2015). The BER (2016), of which SEDA is part, found that despite the establishment of a number of regional support institutions in the last 15 years, the degree for government support provided to founders of existing SMEs was grossly inadequate for the generally low-skilled workforce of 50-60\% of South Africa's citizens (DTI 2016; see also Worku 2016). SEDA (2012) report on the agricultural entrepreneurship policies and practices, also documented challenges related to support infrastructure, access to finance and largely limited knowledge and skills in communities with livelihood strategies of mostly small-scale subsistence agriculture and daily or seasonal labour. These are, in the large majority, people living in rural and semi-urban communities, which oftentimes still provide cheap pools of labour for the established large and mostly still white agribusinesses and international mining companies (Förster et al. 2017). As such, the policy capacity chasm furthermore relates to the largely limited capacity of the supposed beneficiaries of the bioprospecting policy, to understand and utilise the ideas behind it for making a living.

It seems the South African Biodiversity Economy strategy was developed and politically framed as if assuming a set of resources and capabilities, not yet existent in many areas of South Africa: "now they [the government] want them [the rural and urban poor] to become business man, whereas this is exactly what they have never been", said a senior manager from a large Western Cape Province Municipality (Interview O).

The six local producers of Moringa interviewed here, had neither knowledge about the Bioprospecting Economy or any of the related potential opportunities, nor about related legislation and policy. A rural producer near Pretoria explained: "I don't know these things [bioprospecting permit applications] my friend. I just grow and then sell"(Interview P).

Within the focus of this study, the creation of more strategic transformative capacity was largely limited among South African actors from government and the policy target group.

\section{Transformations of policy}

At the time of conducting this research, the South African government had realised that the framework of policy and law devised so far, had not fostered socio-economic developments according to the country's supposedly transformative agenda in the Bioprospecting Economy. Amongst the core reactions to address its sluggish performance was the strengthening of institutional networks with close-to-government organisations in the bioprospecting sector and to revise and adapt the regulations of NEMBA and BABS. As such, a transformation of policy is underway in South Africa, expressing adaptive capacity.

\footnotetext{
${ }^{19}$ During a comparative research project the main author of this paper conducted over 100 interviews related to small agricultural businesses and government supported SME farming projects in agricultural areas in the Northwest and Western Cape Province in South Africa. The biggest obstacles to their small business were described as: limited knowledge about the management and business side of their activities, lack of access to adequate finance, land and water ownership rights, and largely limited capacities in public administration on provincial and municipal level causing large timely delays (Förster 2018).
} 
The South African Council for Scientific and Industrial Research ${ }^{20}$ has been given a stronger role in the process of engaging in bioprospecting activities and in the process of engaging with indigenous communities. The ongoing establishment of a national digital archive for indigenous knowledge in a participatory process with communities (Bagley 2018) might prove as an important approach to fast-track the identification of indigenous knowledge holders and thus ease the permitting system. ${ }^{21}$ Furthermore, the establishment of an organisational network called "bioPANZA" as a political attempt to addressing the challenges of uncoordinated activities of involved players was enacted by political decision makers in 2016, but then tellingly postponed to end of 2019. Also, the DEA website is now providing detailed information on bioprospecting policy and regulations, as well as links to download permit applications, which it did not by the time this research commenced in early 2017. One of the most important means to transform current policy and governance might prove to be the official revision of the BABS regulations in order to make the permit system more conducive for business development. Given some locally successful examples of bioprospecting in terms of job creation documented in recent research (Wynberg et al. 2015), adapting the regulatory instruments might hold potential.

\section{Limitations and challenges}

Due to this papers focus on furthering the existing concept of policy capacity, certain limitations and thematic omissions of this paper must be outlined, especially within the history-laden context of South Africa: the issue of access to natural resources (especially land); infrastructure and technological issues; economic interest of powerful elites access to markets; political ideologies and reservations related to underlying economic paradigms political ontologies, as well as international developments.

A further operationalisation of policy capacity categories as per level of capacity, policy field and actors seems a fruitful academic effort.

\section{Concluding remarks}

In our study about the transformative policy capacity of public and private actors in the implementation of South Africa's developmental policy of a Biodiversity Economy, we found a web of factors limiting its effectiveness. While the reasons are contextually complex and comprise more dimensions than could be covered in this paper, we have identified factors contributing to limited policy capacities of involved bioprospecting actors from government, as well as those from within the policy target group, who were inhibiting a meaningful implementation of the policy in practice. We found policy capacities

\footnotetext{
20 The CSIR is a parastatal research organisation, holding a number of bioprospecting permits. It is the largest on the African country employing around 2000 scientists, engineers and technicians of which around 350 hold a PhD. There exists considerable expertise in engaging with TK-holders and negotiating access and benefits sharing agreements. The CSIR role in the patent trial regarding the Hoodia gordonii appetite suppressant is said to have led (after substantial critique) to a more community-oriented approach in this organisation (Bagley 2018).

21 Concerning this, Chennells et al. (2009) documented that indigenous knowledge and traditional history are often narrative accounts in the form of stories. Adapting existing formal systems of ownership to account for oral history and knowledge held over generations of native African people is brought forward by the authors as an expedient way to govern IP related issues in South Africa.
} 
to be limited on the individual-analytic and the operational-organisational, as well as the systemic-operational level.

The limited organisational-operational capacity found its expression in firstly, largely unclear and overly broad legal definitions of bioprospecting within relevant policy and legislation. This led to practical entrepreneurial uncertainties regarding business operation and timely planning, as well as an overregulation of existing bioprospecting value chains. Secondly, the prevalent limited individual-operational and organisational-operational capacities to deal with the number of permit applications was due to a limited number of staff and limited knowledge about the complexity of the topic in everyday practice. The permit requirements were not distributed along the process of creating value, but were required at a very early stage of a bioprospecting project, placing administrative burdens on potential bioprospecting actors. The regulatory requirements of making a bioprospecting permit mandatory for every single actor in the value chain, from producer to distributor and to manufacturer, etc., were further obstacles involving relatively high costs for permit applicants and timely delays for emerging businesses. The lengthy administrative procedures and bureaucratic requirements of the permit system, were a large barrier for many potential bioprospecting actors, especially the poor, to enter the bioprospecting and natural product business. It was also a limiting factor in the operation of larger domestic as well as international natural product and pharmaceutical companies who required a permit for every step along the value chain. However, whilst smaller businesses were facing bureaucratic challenges, it was found that and expressed by several participants, that more capitalised international companies had established ways to achieve a more privileged access to the permitting system. They were able to pay the non-refundable fee of R 5000 for handing in a bioprospecting application, which was a major inhibitor for poor rural actors and community-based projects. Here, regulation acted as a barrier to transformation.

In terms of systemic policy capacity, we found that a combination of two factors was limiting the transformative impact of the Biodiversity Economy strategy: 1) limited longterm plans for practical economic and financial support from the government towards potential bioprospecting entrepreneurs and 2) the limited knowledge and skills basis of the poor to benefit from what existing policies have to offer. As such, the ability of potential bioprospecting entrepreneurs from the rural poor to access and deal with formal regulations was limited. Furthermore, their business-related knowledge about how to become bioprospecting entrepreneurs was also largely limited, not to mention how to transfer this idea into financially viable action. This was largely due to limited transparency and a lack of awareness raising campaigns, which could have contributed to the building of operational and individual policy capacity, legitimacy and accountability.

Practically, as part of the ongoing evaluation of the Biodiversity Economy that has already been initiated by the South African government, the revision of definitions within the Biodiversity Economy policies and legal documents to increase clarity and tangibility and to include for incorporating knowledge and traditional practices, seems inevitable (transformation of governance). We consider a revision of the permit requirements in relation to the economic realities on the ground and the needs of bioprospecting businesses, in order to make it more practical and conducive, as central. Involving the holders of indigenous knowledge in this policy review process from the beginning onwards could be largely beneficial for its acceptance and legitimacy, while potentially creating knowledge and awareness in a policy intended to introduce alternative livelihood pathways.

On the basis of our empirical findings, we were able to identify capacity criteria for successfully initiating and steering of societal transformations in terms of an inclusive Biodiversity Economy as outlined by the South African Government. First, the incremental fostering of capacitated actors on multiple levels of the society including government officials 
and the policy target group act as a key requirement for initiating transformative processes. Informing the policy target group about the existence of policies, while also accounting for a lack of expedient skills and knowledge of how to use formalised processes by providing support structures of awareness raising and targeted skills development to apply for permits as well as financial support, are equally crucial factors. Second, specialised and technical knowledge in the operative processes of state departments, as well as a sufficient number of knowledgeable staff are pivotal conditions for steering transformations at the intersection of individual-operational and organisational-operational capacity levels. Individual and operational capacity limits outlined in this paper furthermore underline the need to build financial and human resources within governmental departments.

We have outlined in the theoretical sections of this paper that transformations are socially complex, highly contextualised multifaceted and interconnected processes, and we have corroborated this through the research's findings. The building of individual and operational resources and capabilities to understand rather complex problem settings prior to and while implementing such policies is crucial for a transformative policy capacity in the sense of to making expedient choices of resource distribution to achieve the policy goals. Since country-specific contextual factors such as history, socio-economics and aspects of access to natural resources played a central role in how policy played out in practice, we conclude it as central to consider these factors in strategic decisions after assessing the policy context and in developing and implementing more expedient policy and governance arrangements anticipated to foster transformations. Therefore, understanding policy capacity as merely public capacity of state actors is largely limited conceptually and outdated regarding advancements in systems - thinking and scholarly insights on policy and governance outlined earlier. Recognising and acknowledging the policy target group (and other societal actors), as embedded into divers local contexts, and as endowed with certain livelihood resources and capabilities, is a decisive aspect especially in the formulation and practical implementation of policies, and for transformative policy capacity.

Based on the above, we assert the operational-organisational, the systemic-operational as well as the systemic-strategic capacity level to have a pivotal role to play in societal transformative processes. But in order to allow transformative policies to develop initial societal traction, it is necessary to prepare the system for the anticipated change. This starts with the individual and cognitive level of education and the building and sharing of knowledge to develop a sufficient set of skills in central actors-a strategic agency for transformative change.

Acknowledgements Open Access funding provided by Projekt DEAL.

Open Access This article is licensed under a Creative Commons Attribution 4.0 International License, which permits use, sharing, adaptation, distribution and reproduction in any medium or format, as long as you give appropriate credit to the original author(s) and the source, provide a link to the Creative Commons licence, and indicate if changes were made. The images or other third party material in this article are included in the article's Creative Commons licence, unless indicated otherwise in a credit line to the material. If material is not included in the article's Creative Commons licence and your intended use is not permitted by statutory regulation or exceeds the permitted use, you will need to obtain permission directly from the copyright holder. To view a copy of this licence, visit http://creativecommons.org/licenses/by/4.0/.

\section{Appendix}

See Tables 1 and 2 . 


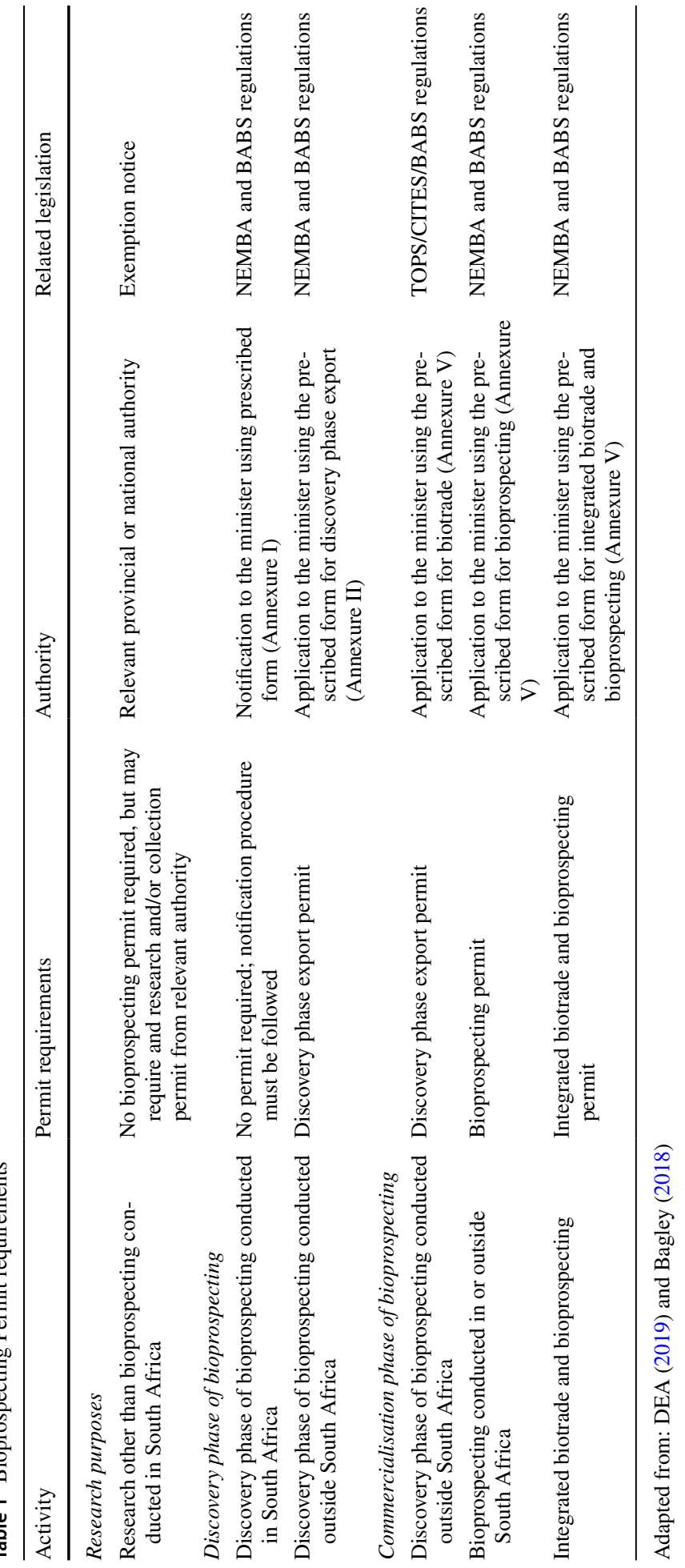




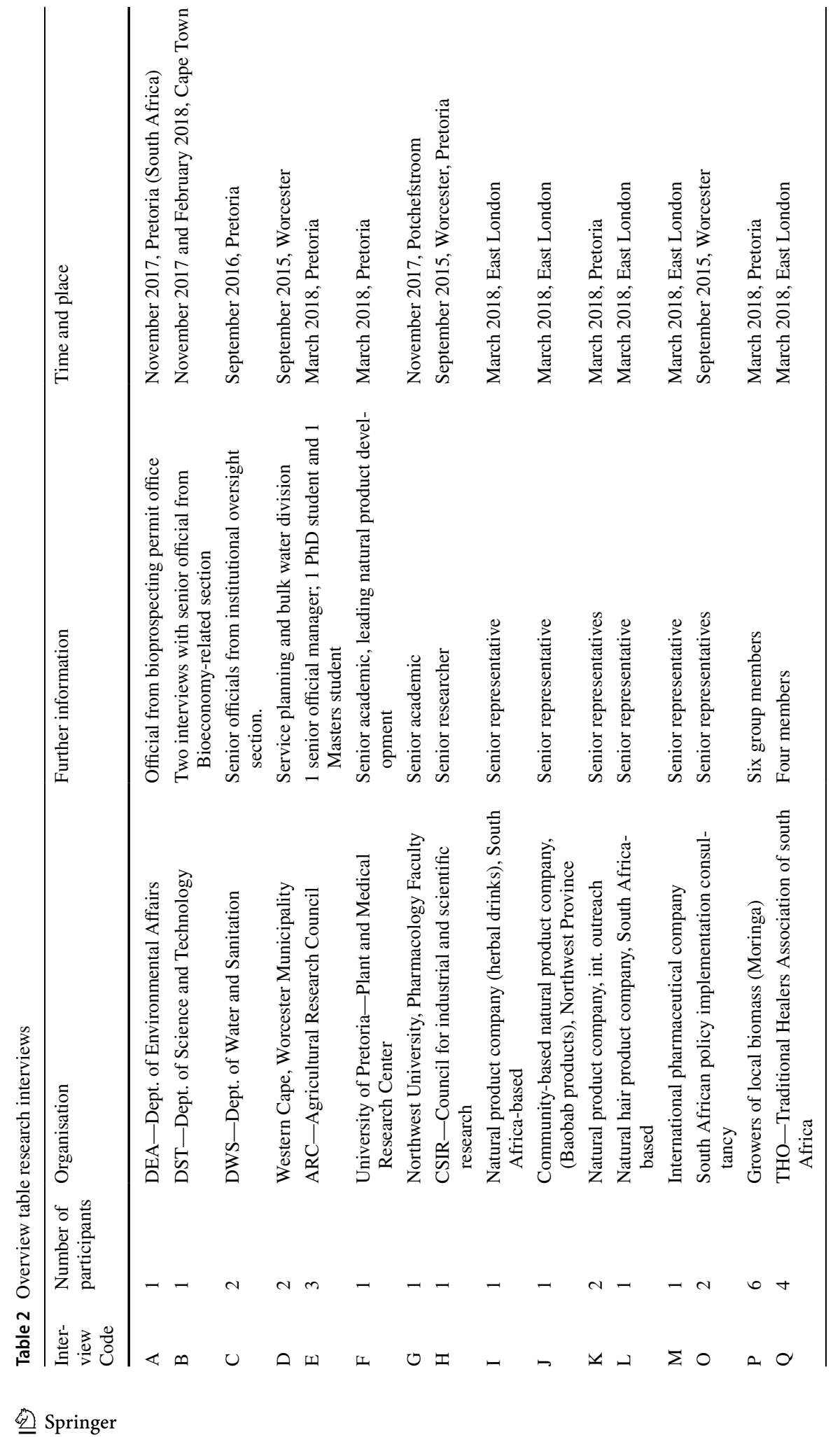




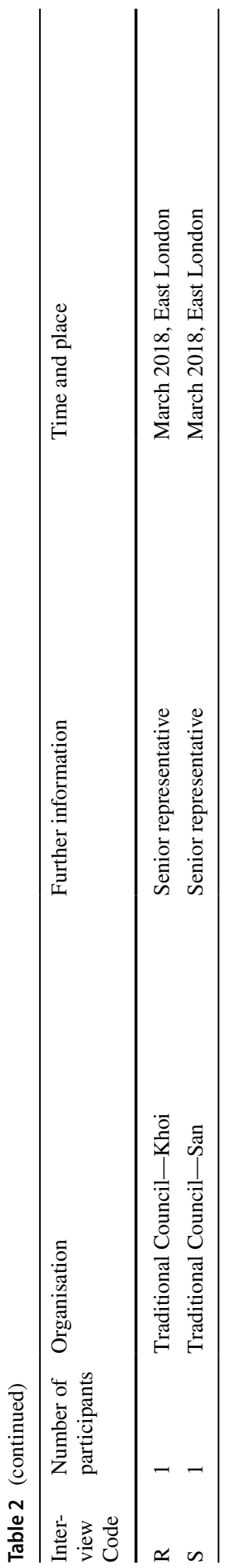




\section{References}

ABSCH (Access and Benefit Clearing House). (2018). Nagoya Protocol Interim National report on the implementation of the Protocol-South Africa. Retrieved from September 2018: https://absch.cbd.int/ en/countries.

Altvater, E. (2009). Pers. comm., Free University of Berlin, June 2009.

Archer, M. (2000). Being human: The problem of agency. Cambridge: Cambridge University Press.

Arnold, T. H., Prentice, C. A., Hawker, L. C., Snyman, E. E., Tomalin, M., Crouch, N. R., et al. (2002). Medicinal and magical plants of Southern Africa: An annotated checklist. Strelitzia 13. Pretoria: National Botanical Institute.

Asah, F., Fatoki, O. O., \& Rungani, E. (2015). The impact of motivations, personal values and management skills on the performance of SMEs in South Africa. African Journal of Economic and Management Studies, 6(3), 308-322.

Babbie, E. (2007). The practice of social research (11th ed.). Belmont: Thomson Wadsworth.

Bagley, M. (2018). Toward an effective indigenous knowledge protection regime case study of South Africa. Retrieved from March 2019 https://www.cigionline.org/search?search_api_fulltext=Bagley\%20 \&sort_by=created.

Benz, A., Lutz, S., Schimank, U., \& Simonis, G. (Eds.). (2007). Handbuch Governance. Wiesbaden: Theoretische Grundlagen und empirische Anwendungsfelder.

BER-Bureau for Economic Research. (2016). The small, medium and micro enterprise sector of South Africa. Research Note 2016, No 1. Stellenbosch University.

Biermann, F., Betsill, M. M., Gupta, J., Kanie, N., Lebel, L., Liverman, D., et al. (2009). Earth system governance. people, places and the planet. Science and implementation plan of the earth system governance project. Earth System Governance Project Report 1. IHDP Report 20. Bonn.

Boelens, R., \& Zwarteveen, M. (2005). Anomalous water rights and the politics of normalization. Paper presented at the ESRC Seminar Politics, Institutions and Participation. Retrieved from May 3, 2007 www.brad.ac.uk/acad/bcid/seminar/water/seminar3/.

Bressers, H. T., \& O’Toole, L. J., Jr. (1998). the selection of policy instruments: A network-based perspective. Journal of Public Policy, 18(3), 213-239.

Brownlie, S., von Hase, A., Botha, M., Manuel, J., Balmforth, Z., \& Jenner, N. (2017). Biodiversity offsets in South Africa-Challenges and potential solutions. Impact Assessment and Project Appraisal, 35(3), 248-256. https://doi.org/10.1080/14615517.2017.1322810.

Bryman, A., \& Cassell, C. (2006). The researcher interview: A reflexive perspective. Qualitative Research in Organizations and Management, 1(1), 41-55.

BTI. (2019). Bertelsmann Transformation Index. (2018). Retrieved from August 2018: https://www.btiproject.org/en/reports/country-reports/detail/itc/zaf/.

Businesstech Newspaper. (2018). Online version of newspaper. Ramaphosa's plan for radical economic transformation and tackling unemployment. Retrieved from April 2019 https://businesstech.co.za/ news/business/222155/ramaphosas-plan-for-radical-economic-transformation-and-tackling-unemp loyment/.

Chaffin, B. C., Garmestani, A. S., Gunderson, L. H. Harm, Benson, M., Angeler, D. G., Arnold, C. A., et al. (2016). Transformative environmental governance. Annual Review of Environment and Resources, 41, 399-423. https://doi.org/10.1146/annurev-environ-110615-085817.

Chapin, F. S., III, Carpenter, S. R., Kofinas, G. P., Folke, C., Abel, N., Clark, W. C., et al. (2009). Ecosystem stewardship: Sustainability strategies for a rapidly changing planet. Trends in Ecology \& Evolution, 25(4), 241-249.

Chennells, R. (2013). Traditional knowledge and benefit sharing after the Nagoya protocol: Three cases from South Africa' 9/2. Law, Environment and Development Journal, 163. Retrieved from February 2019: http://www.lead-journal.org/content/13163.pdf.

Chennells, R., Haraseb, V., \& Ngakaeaja, M. (2009). Speaking for the San: Challenges for Representative Institutions. In R. Wynberg, S. Schroder, \& R. Chennells (Eds.), Indigenous peoples, consent and benefit sharing: Lessons from the San-Hoodia Case. London: Springer.

Chess, C., Hance, B., \& Gibson, G. (2000). Adaptive participation in watershed management. Journal of Soil and Water Conservation, 55.

Cleaver, F. (2012). Development through bricolage, rethinking institutions for natural resources management (1st ed.). London: Routledge.

Creswell, J. W. (2009). Research design: Qualitative, quantitative and mixed methods approaches. London: Sage. 
Crouch, N., Douwel, E. Wolfson, W. M., Smith, G. F., \& Edwards, T. (2008, September/October). South Africa's bioprospecting, access and benefit-sharing legislation: Current realities, future complications, and a proposed alternative. South African Journal of Science 104.

DEA. (2015a). Department of Environmental Affairs. Biodiversity Economy strategy. Government Gazette No. 39368.

DEA. (2015b). Department of Environmental Affairs. Annual Report 2015/16. https://www.environmen t.gov.za/documents/reports. Accessed Jan 2018.

DEA. (2018). Department of Environmental Affairs. Speech by Minister Molewa during official opening of 3rd Biodiversity Indaba. Retrieved from March 2018: https://www.environment.gov.za/speech/molew aopensthirdbiodiversityindaba.

DEA. (2019). Department of Environmental Affairs. Retrieved from March 2018: https://www.environmen t.gov.za/projectsprogrammes/bioprospectingaccess_benefitsharing_babs_clearinghouse.

DEAT. (2004). Department of Environmental Affairs and Tourism. National Environmental Management: Biodiversity Act, NEMBA, Act No. 10 of 2004. Government Gazette No. 26436.

DEAT. (2008). Department of Environmental Affairs and Tourism. Convention on Biological Diversity $(C B D)$. Geneva: United Nations Environment Programme.

DeLeon, P., \& deLeon, L. (2002). Whatever happened to policy implementation? An alternative approach. Journal of Public Administration Research and Theory, 12(4), 467-492.

DeVos, A., Strydom, H., Fouché, C. B., \& Delport, C. S. L. (Eds.). (2012). Research at Grass Roots, for the social sciences and human service professions (4th ed.). Pretoria: Van Schaik.

Dietz, T., Börner, J., Förster, J. J., \& von Braun, J. (2018). Governance of the bioeconomy: A global comparative study of national bioeconomy strategies. Sustainability, 10(9), 3190.

DPME. (2015). Department for Planning, Monitoring and Evaluation (DPME), State of management practices, report. Retrieved from January 2019: https://www.dpme.gov.za/keyfocusareas/Local\%20Gov ernment\%20Performance\%20Assessment/Pages/Reports.aspx?ControlMode=Edit\&DisplayMod $\mathrm{e}=$ Design.

DST. (2013). Department of Science and Technology. The bioeconomy strategy 2013. Retrieved from September 2017: www.dst.gov.za.

DTI, Department of Trade and Industry, South Africa. (2016). SMME Development. Retrieved from February 2017: http://www.thedti.gov.za/.

Du Plooy-Cilliers, F., Davis, C., \& Bezuidenhout, R.-M. (2014). Research matters. Cape Town: Juta.

Edmondson, D., Kern, F., \& Rogge, K. (2018). The co-evolution of policy mixes and socio-technical systems: Towards a conceptual framework of policy mix feedback in sustainability transitions. Research Policy. https://doi.org/10.1016/j.respol.2018.03.010.

EWN. (2018). Eyewitness News website-'Radical economic transformation'. Retrieved from April 2019: https://ewn.co.za/Topic/Radical-economic-transformation.

Flick, U. (2006). An introduction to qualitative research (3rd ed.). London: Sage.

Folke, C., Carpenter, S. R., Walker, B., Scheffer, M., Chapin, T., \& Rockström, J. (2010). Resilience thinking: Integrating resilience, adaptability and transformability. Ecology and Society, 15(4), 20.

Folke, C., Hahn, T., Olsson, P., \& Norberg, J. (2005). Adaptive governance of social-ecological systems. Annual Review of Environment and Resources, 30(1), 441-473.

Forst, R. (2018). Plenary lecture on 'Normativity and reality: Thinking politically about politics. ECPR conference, August 23rd, Hamburg, Germany.

Förster, J. J. (2018). Ruling the game of institutional water governance. An analysis of access, power and control in South Africa. PhD-thesis. Monash University, School of Social and Political Sciences, Melbourne.

Förster, J. J. (2020, April). Condemned to circularity: Thailand's emerging bioplastic industry. ZEF News Journal, ZEF News (forthcoming).

Förster, J. J., Downsborough, L., \& Chomba, M. J. (2017). When policy hits reality: Structure, agency and power in South African water governance. Society \& Natural Resources, 30(4), 521-536. https://doi. org/10.1080/08941920.2016.1268658.

Förster, J. J., \& Virgin, I. (2018). Bioeconomy between Europe and Africa. Summarizing the workshop outcomes. ZEF-Policy Brief No. 29.

Fourie, T. G., Swart, I., \& Snyckers, F. O. (1992). Folk medicine: A viable starting point for pharmaceutical research. South African Journal of Science, 88, 190-192.

Frantzeskaki, N., Loorbach, D., \& Meadowcroft, J. (2012). Governing societal transitions to sustainability. International Journal of Sustainable Development, 15.

Freudenberger, L., Schluck, M., Hobson, P., Sommer, H., Cramer, W., Barthlott, W., et al. (2010). A view on global patterns and interlinkages of biodiversity and human development. In: P. L. Ibisch, A. E. Vega, 
\& T. M. Herrmann (Eds.), Technical Series No. 54: Interdependence of biodiversity and development under global change. Convention on Biological Diversity (pp. 37-56).

Fukuyama, F. (2013). What is governance? Governance, 26(3), 347-368. https://doi.org/10.1111/ gove. 12035 .

Geels, F. W., \& Schot, J. (2010). The dynamics of transitions: A socio-technical perspective. In J. Grin, J. Rotmans, \& J. Schot (Eds.), Transitions to sustainable development new directions in the study of long term transformative change. New York: Routledge.

Giddens, A. (1984). The constitution of society: Outline of the theory of structuration. Oxford: Polity Press.

Given, L. M. (2008). The Sage encyclopedia of qualitative research methods. Thousand Oaks, CA: Sage.

Gleeson, D. H., Legge, D. G., \& O’Neill, D. (2009). Evaluating health policy capacity: Learning from international and Australian experience. Australia and New Zealand Health Policy. https://doi. org/10.1186/1743-8462-6-3.

Gleeson, D., Legge, D., O’Neill, D., \& Pfeffer, M. (2011). Negotiating tensions in developing organizational policy capacity: Comparative lessons to be drawn. Journal of Comparative Policy Analysis: Research and Practice, 13(3), 237-263.

Göpel, M. (2018). The Great Mindshift. How a new economic paradigm and sustainability transformations go hand in hand. Berlin: Springer. https://doi.org/10.1007/978-3-319-43766-8.

Grin, J. (2010). Understanding transitions from a governance perspective. In J. Grin, J. Rotmans, \& J. Schot (Eds.), Transitions to sustainable development: New directions in the study of long term transformative change. New York: Routledge.

Grin, J., Rotmans, J., \& Schot, J. (2010). Transitions to sustainable development: New directions in the study of long term transformative change. New York: Routledge.

GSB. (2018). Graduate School of Business of the University of Cape Town. Radical economic transformation: You can't redistribute what isn't there. Article summary of workshop outcomes. Retrieved from February 2019: https://www.gsb.uct.ac.za/main-article.

Gunderson, L. H., \& Holling, C. S. (2002). Understanding transformations in human and natural systems. Washington, DC: Island Press.

GVR, Grand View Research. (2019). Retrieved from March 2019 https://www.grandviewresearch.com/ press-release/global-organic-personal-care-market.

Houtzagers, G. (1999). Empowerment, using skills and competence management. Participation and Empowerment: An International Journal, 7(2), 27-32. https://doi.org/10.1108/146344499102714 29.

Howlett, M. (2009). Government communication as a policy tool: A framework for analysis. The Canadian Political Science Review, 3(2), 23-37.

Howlett, M., \& Lindquist, E. (2004). Policy analysis and governance: Analytical and policy styles in Canada. Journal of Comparative Policy Analysis: Research and Practice, 6(3), 225-249.

Howlett, M., \& Ramesh, M. (2015). Achilles' heels of governance: Critical capacity deficits and their role in governance failures: The Achilles heel of governance. Regulation \& Governance. https:// doi.org/10.1111/rego.12091.

Kooimann, J. (2003). Governing as governance. California: Sage.

Ladzani, W. M., \& Netswera, G. F. (2009). Support for rural Small Businesses in Tshwane, South Africa. Development Southern Africa, 26(2), 14-21.

Laird, S., McLain, R., \& Wynberg, R. (Eds.). (2010). Wild product governance: Finding policies that work for non-timber forest products. London: Earthscan.

Lall, N. (2018). Medicinal plants for holistic health and well-being. London: Academic Press, Elsevier.

Lipsky, M. (1980). Street level bureaucracy: Dilemmas of the individual in public services. New York: Russel Sage Foundation. https://doi.org/10.7758/9781610447713.

Loorbach, D. (2009). Transition management for sustainable development: A prescriptive, complexitybased governance framework. Governance, 23(1), 161-183.

Loorbach, D., \& Rotmans, J. (2010). The practice of transition management: Examples and lessons from four distinct cases. Futures, 42, 237-246.

Markard, J., Raven, R., \& Truffer, B. (2012). Sustainability transitions: An emerging field of research and its prospects. Research Policy, 41(6), 955-967.

Meadowcroft, J. (2009). What about the politics? Sustainable development, transition management, and long-term energy transitions. Policy Sciences, 42, 323-340.

Monkelbaan, J. (2019). Governance for the sustainable development goals. Exploring an integrative framework of theories, tools and competencies. Berlin: Springer.

Muno, W. (2007). Harold D. Lasswell. Politics: Who gets what, when, how. Cleveland/New York 1936. In S. Kailitz (Eds.), Schlüsselwerke der Politikwissenschaft.VS VerlagfürSozialwissenschaften. 
News24. (2019). Articles relating to land expropriation without compensation. Retrieved from March 2019: https://www.news24.com/Tags/Topics/land_expropriation_without_compensation.

Nkahta, B. A., Breen, C., Downsborough, L., Mosimane, A., \& Roux, D. (2012). A typology for benefit sharing arrangements for the governance of socio-ecological systems in developing countries. Ecology and Society, 17(1), 17. https://doi.org/10.5751/ES-04662-170117.

North, D. (1990). Institutions, institutional change and economic performance. Cambridge: Cambridge University Press.

OECD. (2008). OECD Review of Agricultural Policies - South Africa.

OECD. (2015). Effective Institutions. OECD and post-2015 reflections. Retrieved from March 2019: https://www.oecd.org/dac/_POST-2015\%20effective\%20and\%20accountable\%20institutions.pdf.

OECD, Organisation for Economic Cooperation and Development. (2012). International Futures Programme, The Bioeconomy to 2030: Designing a Policy Agenda 3, based on the European Commission's COM (2012).

OECD, Organization for Economic Cooperation and Development. (2006). The challenge of capacity development: Working towards good practice. Retrieved from November 2007: http://www.gsdrc .org/docs/open/CC110.pdf.

Olsson, P., Folke, C., \& Hahn, T. (2004). Social-ecological transformation for ecosystem management: The development of adaptive co-management of a wetland landscape in southern Sweden. Ecology and Society, 9(4), 2.

Olsson, P., Gunderson, L. H., Carpenter, S. R., Ryan, P., Lebel, L., Folke, C., et al. (2006). Shooting the rapids: Navigating transitions to adaptive governance of social-ecological systems. Ecology and Society, 11(1), 18.

Pahl-Wostl, C. (2009). A conceptual framework for analysing adaptive capacity and multi-level learning processes in resource governance regimes. Global Environmental Change, 19(1), 354-365.

Painter, M., \& Pierre, J. (Eds.). (2005). Challenges to state policy capacity: Global trends and comparative perspectives. London: Palgrave Macmillan.

PMG, Parliamentary Monitoring Group. (2018a). Biodiversity and coastal and marine tourism delivery lab. Retrieved from January 2019: https://pmg.org.za/files/161018BIODIVERSITY_LAB.doc.

PMG, Parliamentary Monitoring Group. (2018b). Briefing notes for the portfolio meeting on environmental affairs on the biodiversity and coastal and marine tourism delivery lab. Document link, Retrieved from July 2018: www.pmg.org.za/files/161018BIODIVERSITY_LAB.doc.

Parsons, W. (2004). Not just steering but weaving: Relevant knowledge and the craft of building policy capacity and coherence. Australian Journal of Public Administration, 63(1), 43-57.

Patterson, J., Schulz, K., Vervoort, J., van der Hel, S., Widerberg, O., Adler, C., et al. (2016). Exploring the governance and politics of transformations towards sustainability. Environmental Innovation and Societal Transitions. https://doi.org/10.1016/j.eist.2016.09.001.

Peters, G. (2015). Policy capacity in public administration. Policy and Society, 34(3-4), 219-228. https:// doi.org/10.1016/j.polsoc.2015.09.005.

Peters, G., \& Pierre, J. (2007). Institutionalism (Vol. 4). London: Sage Library of Political Sciences.

Polanyi, K. (2001). The great transformation: The political and economic origins of our time. Boston, MA: Beacon Press. (1944).

Polkinghorne, D. E. (2005). Language and meaning: Data collection in qualitative research. Journal of Counseling Psychology, 52(2), 137-145.

Quibble, G., Stein, R., Seetal, A., \& N. Capayi, N. (2012). Transforming legal access to water to redress social inequity and economic efficiency (pp. 97-119). In Schreiner, B., \& Hassan, R. 2011. (see below).

Raworth, K. (2012). A safe and just space for humanity. OXFAM Discussion papers, February 2012.

Ribot, J. (2009). Authority over forests: Empowerment and subordination in Senegal's democratic decentralization. Development and Change, 40(1), 105-129.

Rockström, J., Steffen, W., Noone, K., Persson, A.,Chapin III, F. S., Lambin, E., et al. (2009). A safe operating space for humanity. Nature, 461(7263), 472-475. https://doi.org/10.1038/461472a.

Rogge, K. S., \& Reichardt, K. (2016). Policy mixes for sustainability transitions: An extended concept and framework for analysis. Research Policy, 45, 1620-1635.

Rotberg, R. I. (2014). Good governance means performance and results. Governance. https://doi. org/10.1111/gove. 12084 .

Rotmans, J., \& Loorbach, D. (2009). Complexity and transition management. Journal of Industrial Ecology, 13(2), 184-196.

Rueschemeyer, D. (2009). Usable Theory, analytic tools for social and political research. New Jersey: Princeton University Press.

Sabatier, P., \& Jenkins-Smith, H. (1993). Special issue: Policy change and policy-oriented learning: Exploring an advocacy coalition framework. Policy Sciences, 21, 123-272. 
Sachs, J., Schmidt-Traub, G., Kroll, C., Lafortune, G., \& Fuller, G. (2019). Sustainable Development Report 2019. New York: Bertelsmann Stiftung and Sustainable Development Solutions Network (SDSN).

Schot, J., \& Geels, F. W. (2008). Strategic niche management and sustainable innovation journeys: Theory, findings, research agenda, and policy. Technology Analysis \& Strategic Management, 20(5), 537-554.

Schot, J., \& Kanger, L. (2018). Deep transitions: Emergence, acceleration, stabilization and directionality. Research Policy, 47, 1045-1059.

Schreiner, B. (2013). Viewpoint-Why has the South African national water act been so difficult to implement? Water Alternatives, 6(2), 239-245.

Schreiner, B., \& Hassan, R. (2011). Transforming water management in South Africa. Designing and implementing a new policy framework. Global Issues in water policy 2. Berlin: Springer.

Scoones, I., Leach, M., \& Newell, P. (Eds.). (2015). The politics of green transformations. London: Routledge.

SEDA. (2012). South African Small Enterprise Development Agency. Research on the performance of the agriculture sector. http://www.seda.org.za/Publications/Pages/Research-Publications.aspx.

SEDA. (2015). South African Small Enterprise Development Agency (SEDA). SAIE learning loop: Why the loop? Retrieved from November 2016: www.entrepreneurship.co.za/.

Shove, E., \& Walker, G. (2010). Governing transitions in the sustainability of everyday life. Research Policy, 39, 471-476. https://doi.org/10.1016/j.respol.2010.01.019.

Shree, S., \& Urban, B. (2012). Internationalisation of South African SMEs: The role of capital factors. Acta Commercii, 12(1), 186-199.

Smallbone, D., Lieg, R., \& North, D. (1995). The characteristics and strategies of high growth SMEs. International Journal of Entrepreneurial Behaviour and Research, 1(3), 44-62.

Smedlund, A. (2008). The knowledge system of a firm: Social capital for explicit, tacit and potential knowledge. Journal of Knowledge Management, 12(1), 63-77.

Smith, A., \& Stirling, A. (2010). The politics of social-ecological resilience and sustainable socio-technical transitions. Ecology and Society, 15(1), 11.

StatsSA. (2019). Quarterly Labour Force Survey, Quarter 3. http://www.statssa.gov.za/?p=12689. Accessed Feb 2020.

Svensson, O., \& Nikoleris, A. (2018). Structure reconsidered: Towards new foundations of explanatory transitions theory. Research Policy, 47(2), 462-473.

Swatuk, L. (2008). A political ecology of water in Southern Africa. Water Alternatives, 1(1), $24-47$.

Tallberg, J. (2002). Paths to compliance: Enforcement, management and the European Union. International Organization, 56(3), 609-643.

UEBT, Union of Ethical Biotrade. (2017). ABS Fact Sheet South Africa. Retrieved from January 2018 https ://www.ethicalbiotrade.org/resources.

UNEP. (2018). Environmental Governance Program 2018-2021. Retrieved from February 2019: https:// wedocs.unep.org/bitstream/handle/20.500.11822/22721/SP\%204\%20-\%202018-2021_Environmen tal\%20Governance $\% 20$ Programme $\% 20$ Framework $\% 20$.pdf?sequence=31\&isAllowed=y.

United Nations (UN) (2013). Human Development Report 2013. Retrieved from August 4, 2014: http://hdr. undp.org/en/2013-report.

van der Molen, F. (2018). How knowledge enables governance: The coproduction of environmental governance. Environmental Science \& Policy, 87, 18-25.

van Koppen, B., Schreiner, B., \& Fakir, S. (2011). The political and economic context and changing water policy in South Africa post-1994. In B. Schreiner \& R. Hassan (Eds.), Transforming water management in South Africa. Designing and implementing a new policy framework. Global Issues in Water Policy 2. Berlin: Springer.

Westley, F. R., Tjornbo, O., Schultz, L., Olsson, P., Folke, C., Crona, B., et al. (2013). A theory of transformative agency in linked social-ecological systems. Ecology and Society, 18(3), 27. https://doi. org/10.5751/ES-05072-180327.

WGI. (2019). World Governance Index of the World Bank. Retrieved from March 2019: https://info.world bank.org/governance/wgi/\#home.

Worku, Z. (2016). The impact of overregulation on small enterprises. Risk governance \& control: Financial markets \& institutions 6: 3, (Special issue Risk Management and Corporate Governance in African Countries).

Wu, X., Ramesh, M., \& Howlett, M. (2015). Policy capacity: A conceptual framework for understanding policy competences and capabilities. Policy and Society, 34, 3-4. https://doi.org/10.1016/j.polso c.2015.09.001.

Wynberg, R., Taylor, M., \& Laird, S. (2007). Access and benefit sharing in South Africa: An analysis of legal frameworks and agreements. DEAT Report No. 1/07/274. 
Wynberg, R., van Niekerk, J., \& Kozanayi, W. (2015). Formalisation of natural product trade in Southern Africa: Unintended consequences and policy blurring biotrade and bioprospecting. Society \& Natural Resources, 28, 559-574.

Publisher's Note Springer Nature remains neutral with regard to jurisdictional claims in published maps and institutional affiliations. 